\title{
Influência dos parâmetros instrumentais sobre o desempenho de coluna de HPLC com partículas superficialmente porosas sub-3 $\mu \mathrm{m}$
}

\author{
Maura Roquete Amparo, Camila Deixum Franzini, Bruna Schiavon, \\ Lucas Sponton de Carvalho, Álvaro José dos Santos Neto* \\ Instituto de Química de São Carlos, Universidade de São Paulo - USP, \\ Av. Trabalhador São-carlense, 400, Cep 13560-970, São Carlos, SP, Brasil \\ e-mail: alvarojsn@iqsc.usp.br
}

Resumo

O interesse por sistemas e colunas cromatográficas que permitem análises mais rápidas tem crescido nos últimos anos. Recentemente, a introdução de colunas com partículas superficialmente porosas sub-3 $\mu \mathrm{m}$ mostrou-se como uma alternativa interessante aos sistemas e colunas de UHPLC que operam em pressões próximas ou superiores a 1000 bar. Essas novas colunas têm apresentado eficiências próximas às de colunas UHPLC mencionadas acima, porém sob menores pressões, possibilitando ainda análises mais rápidas do que em HPLC tradicional. Um aspecto importante do uso de colunas com mais alta eficiência é o aumento da demanda por sistemas de cromatografia com uma reduzida dispersão extracoluna das bandas cromatográficas. Nesse contexto, esse artigo apresenta a avaliação do efeito de diversos parâmetros relacionados com a dispersão extracoluna sobre o desempenho de uma coluna preenchida com partículas superficialmente porosas, dando sequência ao artigo publicado na edição anterior, o qual trazia uma detalhada discussão sobre o papel desempenhado por cada um desses parâmetros.

Palavras-chave

HPLC; partículas superficialmente porosas; volume extracoluna; eficiência; instrumentação.

\section{Influence of instrumental parameters on the performance of HPLC column packed with superficially porous particles sub- $3 \mu \mathrm{m}$}

Abstract

There is a growth interest in chromatographic systems and columns that allow faster analysis. Recently, the introduction of sub- $3 \mu \mathrm{m}$ superficially porous particles has been showing an interesting alternative to UHPLC systems and columns, which work at pressures of about 1000 bar. The chromatographic efficiency of these new columns have been almost reaching that one of the above mentioned UHPLC columns, but under lower pressures; moreover, they have been allowing faster analyses than those obtained with traditional HPLC. A relevant aspect of using very high efficient columns is the increased demand for HPLC systems with reduced extracolumn dispersion of the chromatographic bands. In this context, this article presents the evaluation of the effects of several parameters on the performance of columns packed with superficially porous particles, forwarding the article published in the previous edition, which brought a detailed discussion about the hole of each of those parameters.

Keywords

HPLC; superficially porous particles; extra-column volume; efficiency; instrumentation. 


\section{Introdução}

Tem havido um grande interesse no tipo de análise por HPLC (Cromatografia Líquida de Alta Eficiência), atualmente denominada como "ultrarrápida". Em complementação à já consolidada UHPLC (Cromatografia Líquida de Ultraeficiência), a qual utiliza pressões incompatíveis com a HPLC tradicional, a recente introdução de colunas preenchidas com partículas superficialmente porosas sub-3 $\mu \mathrm{m}$ (as quais têm sido denominadas "SPP sub-3 $\mu$ m", do inglês superficially porous particles) tornou possível análises eficientes e em um tempo mais curto em sistemas HPLC limitados a pressões mais baixas do que as usadas em UHPLC.

O desempenho geral da maior parte das separações cromatográficas pode ser prejudicado pelos efeitos do "volume extracoluna" (ECV) e algumas más configurações da aquisição e tratamento do sinal do detector. Conforme discutido no artigo dessa seção publicado na última edição, vários parâmetros instrumentais de um HPLC convencional, se não forem ajustados apropriadamente, podem prejudicar a eficiência intrínseca das modernas colunas SPP sub-3 $\mu \mathrm{m}$. No artigo anterior, foi feita uma discussão sobre o papel desses parâmetros frente à eficiência cromatográfica, por meio do aumento da dispersão extracoluna das bandas cromatográficas ${ }^{[1]}$.

Uma vez que, em sistemas de cromatografia rápida, os picos eluem em tempos mais curtos, em bandas com um pequeno volume em relação a separações convencionais, modificações devem ser feitas em um HPLC convencional, para que o máximo da eficiência das colunas possa ser obtido durante a análise.

Diferentes recomendações visando melhorar o resultado das separações cromatográficas vêm sendo sugeridas, principalmente em manuais de empresas que vendem produtos para cromatografia ${ }^{[2-5]}$, na maior parte, empresas que oferecem colunas cromatográficas. Dentre as recomendações existentes, algumas são bastante pertinentes como:

1. Ajustes nas condições de detecção. Uma sugestão é diminuir o tempo de resposta do detector e aumentar a frequência de aquisição de dados.

2. Substituir a tubulação do equipamento por tubos de menor comprimento $\mathrm{e}$ diâmetro interno.

3. Substituir uma célula de detecção convencional por uma de menor volume.

4. Adequar o volume de injeção da amostra.

Os ajustes das condições de detecção estão relacionados com três parâmetros: a taxa de aquisição de dados do detector, o seu tempo de resposta e o volume interno da célula de detecção.

Os detectores necessitam ter a diminuição do volume da célula para manter a concentração e o sinal analítico (baixa dispersão da amostra), mantendo ainda o maior possível caminho óptico, a fim de se obter alta detectabilidade. A constante de tempo do detector deve ser suficientemente rápida ( $\leq 100 \mathrm{~ms}$ ) devido às estreitas larguras de base dos picos (apenas poucos segundos) e às altas taxas de amostragem e aquisição dos dados que são necessárias para adquirir dados suficientes em curto espaço de tempo; assim os eventos de aquisição e tratamento eletrônico-computacional dos dados são ajustados de forma a obter um número mínimo de pontos de aquisição ao longo do pico cromatográfico (geralmente 20) e minimizar significadamente o ruído da linda de base sem, ao mesmo tempo, provocar o alargamento dos picos ${ }^{[6]}$.

Para as tubulações do equipamento (todas entre o injetor e o detector) é recomendada a substituição por tubos com d.i. de $127 \mu \mathrm{m}$ $(0,005$ ”) com o menor comprimento possível. Esses tubos contribuem com ECV de apenas $0,13 \mu \mathrm{L} \cdot \mathrm{cm}^{-1}$, o qual é mais compatível com os 
sistemas otimizados. Não se recomendam tubos ainda mais estreitos, pois eles apresentam maior facilidade de obstruções e elevam de maneira incompatível a pressão extracoluna do equipamento. Contudo, em equipamentos configurados para colunas com menor diâmetro interno, tubos ainda mais estreitos podem ser requeridos.

A injeção da amostra é crítica mesmo nos casos de análises por HPLC convencional. No caso de sistemas com colunas mais eficientes, a introdução da amostra torna-se ainda mais crítica. O volume de injeção de amostra deve ser reduzido com a finalidade de evitar o espalhamento da amostra e, consequentemente, o alargamento do pico cromatográfico.

Neste artigo, uma coluna preenchida com partículas SPP sub-3 $\mu \mathrm{m}$ foi utilizada de maneira a avaliar o efeito de diferentes parâmetros presentes em um HPLC tradicional. Teve-se por objetivo ilustrar numericamente e visualmente esses efeitos sobre a eficiência cromatográfica ou sobre parâmetros derivados dela. Com essa abordagem, pretende-se racionalizar a escolha dos parâmetros instrumentais para a análise com o objetivo de não prejudicar substancialmente a eficiência, contudo sem sacrificar outras características cromatográficas, tais como as limitações de pressão do equipamento e a relação sinal/ ruído dos picos cromatográficos obtidos.

\section{Materiais e métodos}

\subsection{Padrões e reagentes}

Foram utilizados padrões analíticos de uracila, naftaleno, antraceno, fenantreno, pireno, levofloxacina, pefloxacina, ciprofloxacina, enrofloxacina, sulfacetamida, sulfadiazina, sulfatiazol, sulfamerazina, sulfametazina, sulfametazol, sulfacloropiridazina, sulfametoxazol, sulfadimetoxina e sulfaquinoxalina. A partir de soluções-estoque em solventes apropriados, foram prepa- radas soluções diluídas de trabalho na fase móvel das análises. Os respectivos padrões foram agrupados em três misturas, de acordo com as suas classes, os hidrocarbonetos policíclicos aromáti$\cos (\mathrm{PAH})$, as fluoroquinolonas (FQ) e as sulfonamidas (SF). Utilizou-se, no preparo das fases móveis, água ultrapurificada, acetonitrila (grau HPLC) e, eventualmente, ácido fórmico (grau analítico).

\subsection{Sistemas cromatográficos e coluna}

Foram usados dois sistemas HPLC convencionais da série 20A Prominence, Shimadzu, contendo bombas LC-20AD, amostrador automático SIL-20A e -20AC, forno para colunas CTO-20A e detector UV-Vis SPD-20A, entre outros dispositivos. Adicionalmente, em alguns experimentos, utilizou-se um injetor manual Rheodyne, modelo 7725i, com alça de amostragem de $20 \mu \mathrm{L}$. Utilizou-se uma coluna com partículas SPP do tipo Poroshell 120 EC-C18 $(100 \times 3,0 \mathrm{~mm}, 2,7 \mu \mathrm{m})$, Agilent, precedida por um filtro pré-coluna de baixa dispersão $(2 \mu \mathrm{m})$ do mesmo fabricante.

Uma vez que foram avaliadas diferentes condições cromatográficas e instrumentais, adequadas a cada experimento, os detalhes pertinentes a cada situação serão apresentados junto aos seus respectivos resultados e discussões.

\subsection{Parâmetros cromatográficos avaliados}

Inicialmente foram comparados dois sistemas cromatográficos da mesma série com arranjos instrumentais diferentes. Cada sistema foi configurado com o menor volume extracoluna possibilitado pelo arranjo instrumental do equipamento (denominados HPLC 1 e HPLC 2), utilizando ainda as condições de detecção que propiciassem o menor alargamento da banda cromatográfica. A seguir foi avaliado o efeito, 
sobre a eficiência, da presença do filtro pré-coluna de baixa dispersão precedendo a coluna analítica, optando-se por utilizá-lo em todas as análises subsequentes.

\subsubsection{Teste 1 - avaliação do volume da célula de detecção e influência da vazão sobre a eficiência, resolução e relação sinal/ruído dos picos cromatográficos}

Após os testes preliminares, foi utilizado o sistema HPLC 2 no restante dos experimentos. Foram comparadas as eficiências do injetor manual e do amostrador automático, sob condições ótimas, para os picos dos $\mathrm{PAH}$, injetando-se $2 \mu \mathrm{L}$ de solução em ambos os casos, constatando-se ausência de diferenças entre ambos. Com as condições de detecção que propiciam o menor alargamento da banda cromatográfica (frequência de aquisição de $10 \mathrm{~Hz}$ e tempo de resposta de 0,02 segundos), foram construídos gráficos de van Deemter para os analitos naftaleno e pireno, comparando uma célula de detecção convencional $(12 \mu \mathrm{L}$ de volume e $10 \mathrm{~mm}$ de caminho óptico) e uma célula de detecção semimicro $(2,4 \mu \mathrm{L}$ de volume e $3 \mathrm{~mm}$ de caminho óptico). Primeiramente, foi utilizado o injetor manual, o qual permitia a utilização de pressões de até 400 bar no sistema HPLC; a seguir, para as outras curvas comparativas, foi utilizado o amostrador automático, limitando a pressão máxima do sistema em pouco mais do que 200 bar.

A partir desses experimentos, foram calculadas as eficiências para os picos do naftaleno e pireno na separação isocrática dos $\mathrm{PAH}$, sendo também construídas curvas de van Deemter. Adicionalmente, considerando todos os analitos da mistura dos $\mathrm{PAH}$, foi feita curva das variâncias dos picos cromatográficos em função dos respectivos volumes de retenção para estimativa da variância extracoluna e da eficiência média intrínseca da coluna. Para a vazão de maior eficiência cromatográfica, foi feita a comparação entre as eficiências e a relação sinal/ruído obtidas com ambas as células. Foram também comparados os cromatogramas da mistura de FQ, em análise por gradiente, de maneira a observar o efeito da célula de detecção sobre a resolução do cromatograma.

\subsubsection{Teste 2 - avaliação da frequência e tempo de resposta do detector sobre a eficiência, resolução e relação sinal/ruídos dos picos cromatográficos}

Foram obtidos cromatogramas nas condições de $10 \mathrm{~Hz}$ e 0,02 segundos; $3,3 \mathrm{~Hz}$ e 0,02 segundos; $3,3 \mathrm{~Hz}$ e 0,5 segundos; e 1,0 Hz e 1,0 segundo. Por meio desses resultados, foi feita comparação das eficiências e relações sinal/ruído para os picos do naftaleno e pireno.

\subsubsection{Teste 3 - avaliação do volume da tubulação sobre eficiência e resolução dos picos cromatográficos}

Foram utilizadas três diferentes tubulações de ligação entre a válvula do amostrador automático e a entrada da coluna. As duas primeiras foram constituídas de tubulação PEEK "vermelha", com $127 \mu \mathrm{m}$ de diâmetro interno, uma com $30 \mathrm{~cm}$ de comprimento e aproximadamente 3,8 $\mu \mathrm{L}$ de volume interno, e a outra com $60 \mathrm{~cm}$ e aproximadamente 7,6 $\mu \mathrm{L}$; adicionalmente foi avaliada tubulação PEEK "alaranjada", com $508 \mu \mathrm{m}$ de diâmetro interno e $30 \mathrm{~cm}$ de comprimento, com aproximadamente $60,8 \mu \mathrm{L}$ de volume interno. Em todas as situações, foram calculadas as eficiências para os picos do naftaleno e pireno na mistura dos PAH e comparadas as resoluções com os cromatogramas das FQ e SF. 


\subsubsection{Teste 4 - avaliação do volume de injeção e efeito focalizador do gradiente sobre a eficiência, resolução e relação sinal/ruído dos picos cromatográficos}

Foram avaliadas injeções de 1, 2, 5 e $10 \mu \mathrm{L}$ utilizando-se o amostrador automático. Conforme, anteriormente, foram avaliadas as eficiências e relações sinal/ruído para os picos do naftaleno e pireno na mistura dos PAH. Adicionalmente, visualmente foram comparadas as diferentes eficiências por meio da superposição dos picos cromatográficos de interesse, com o ajuste da escala dos cromatogramas. No caso das injeções em gradiente, com mistura das FQ e SF, foi possível ainda visualizar o efeito da focalização dos analitos, comparando os primeiros picos com os últimos picos eluídos no cromatograma.

\subsubsection{Demais ajustes e avaliações das condições cromatográficas}

De maneira a obter menor pressão cromatográfica no sistema e, consequentemente, trabalhar em maiores vazões, mesmo sob restritas limitações de pressão máxima, foram avaliadas as separações a 30 e a $40{ }^{\circ} \mathrm{C}$, bem como o comportamento cromatográfico e vazões máximas alcançadas em cada situação.

\section{Resultados e discussões}

Selecionou-se uma coluna SPP sub-3 com dimensões de $100 \times 3,0 \mathrm{~mm}$. Colunas com 3,0 $\mathrm{mm}$ de diâmetro têm sido denominadas "solvent saver" por apresentarem um consumo menor de fase móvel em relação a colunas de diâmetro interno convencional de $4,6 \mathrm{~mm}$, ao mesmo tempo em que não possuem condições tão exigentes de instrumentação (a respeito dos volumes extracolunas) como as colunas semi- micro de 2,1 mm de diâmetro. Apenas como uma referência inicial, as colunas "solvent saver" requerem uma vazão de $0,43 \mathrm{~mL} / \mathrm{min}$ para equivalerem em velocidade linear de análise a uma coluna similar com 4,6 mm de diâmetro a $1,0 \mathrm{~mL} / \mathrm{min}$.

Os sistemas HPLC 1 e 2 utilizados estavam configurados em arranjos instrumentais ligeiramente diferentes. Portanto, foram feitas comparações entre ambos de maneira a verificar se pequenas modificações no posicionamento dos módulos cromatográficos poderiam provocar uma diferença perceptível na eficiência cromatográfica. Uma vez que ambos os equipamentos estavam configurados em suas condições ótimas de eficiência no momento das análises, não foi possível observar diferenças na eficiência e perfil cromatográfico entre ambos os equipamentos, demonstrando que, de fato, ambos poderiam ser usados adequadamente com a coluna em questão. Por questões de facilidade de acesso para modificações nas configurações instrumentais, optou-se então por realizar o restante dos experimentos de configuração instrumental no denominado HPLC 2.

Atualmente tem sido recomendado o uso de filtros pré-coluna como forma de prevenção à obstrução dos frits de entrada da coluna, sem que seja adicionado um excesso de volume extracoluna, como os que são causados por pré-colunas incompatíveis. Neste trabalho, optou-se pelo uso de um filtro de baixa dispersão, tido como apropriado para o tipo de coluna utilizado. Conforme pode ser observado pelas bandas cromatográficas comparadas (Figura 1), com e sem a presença do filtro pré-coluna, nenhuma diferença foi percebida com relação ao alargamento das bandas e consequente perda de eficiência. Dessa forma, foi confirmada a adequação do filtro pré-coluna à sua finalidade, tendo ele sido mantido no restante dos experimentos. 


\subsection{Avaliação do teste 1 - volume da célula de detecção}

Apesar de as bombas e demais configurações dos sistemas HPLC utilizados serem compatíveis com pressões de até $400 \mathrm{bar}$, os amostradores automáticos utilizados eram limitados a pressões de aproximadamente 200 bar, fato esse que limitaria a utilização da coluna analítica até um terço de sua pressão máxima de trabalho (600 bar). Dessa forma, para avaliação da coluna em velocidades mais altas de análise, na construção das curvas de van Deemter, uma válvula de injeção manual também foi utilizada. Com essa configuração, a coluna analítica pode ser operada até vazões de $1,3 \mathrm{~mL} / \mathrm{min}$, sem ultrapassar a pressão de 400 bar (em condições de análise similares àquelas do cromatograma da Figura 1). Em sistemas HPLC mais modernos, os quais suportam pressões mais altas, vazões ainda maiores podem ser utilizadas, até o limite de 600 bar. Com relação à eficiência cromatográfica, não foram observadas diferenças entre a injeção manual e a injeção automática de volumes de $2 \mu \mathrm{L}$ de amostra nas condições ótimas de vazão.

A Figura 2 mostra uma comparação entre as eficiências obtidas para os picos do naftaleno e pireno nos seus máximos de eficiência (segundo o gráfico de van Deemter), a 0,8 e $0,7 \mathrm{~mL} / \mathrm{min}$ de vazão, respectivamente. Como pode ser observado, há uma perda de $7,8 \%$ na eficiência do pico mais retido (pireno) e de $9,9 \%$ no menos retido (naftaleno). Todavia, a escolha da melhor célula de detecção deve ser feita com cuidado, pois o uso de uma célula semimicro pode levar a uma menor razão sinal/ruído para os picos registrados. Por exemplo, nos experimentos realizados para o pireno, na Figura 2, houve uma redução de $20,8 \%$ na intensidade observada para o pico cromatográfico e o dobro da intensidade do ruído na linha de base,

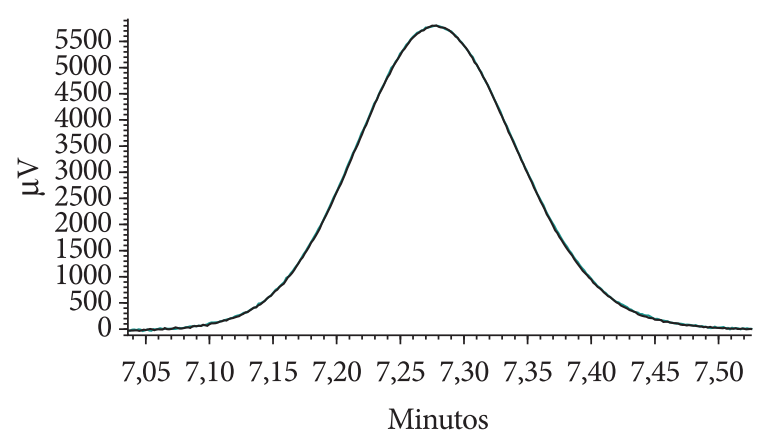

Figura 1 Avaliação da utilização de um filtro précoluna de baixa dispersão precedendo a coluna analítica. a) banda cromatográfica preta (por cima) - Análise com a utilização do filtro; e b) banda cromatográfica verde (por baixo) - Análise sem a utilização do filtro. Destaque para o pico do antraceno, normalizado para a mesma altura, de maneira a favorecer a comparação da largura da banda. Condições gerais: detecção a $10 \mathrm{~Hz}$, filtro de resposta de 0,02 segundos, vazão de $0,4 \mathrm{~mL} / \mathrm{min}$ de mistura $A C N: \mathrm{H}_{2} \mathrm{O}, 60: 40(\mathrm{v} / \mathrm{v})$, volume de injeção de $2 \mu \mathrm{L}$ e temperatura do forno a $30^{\circ} \mathrm{C}$.

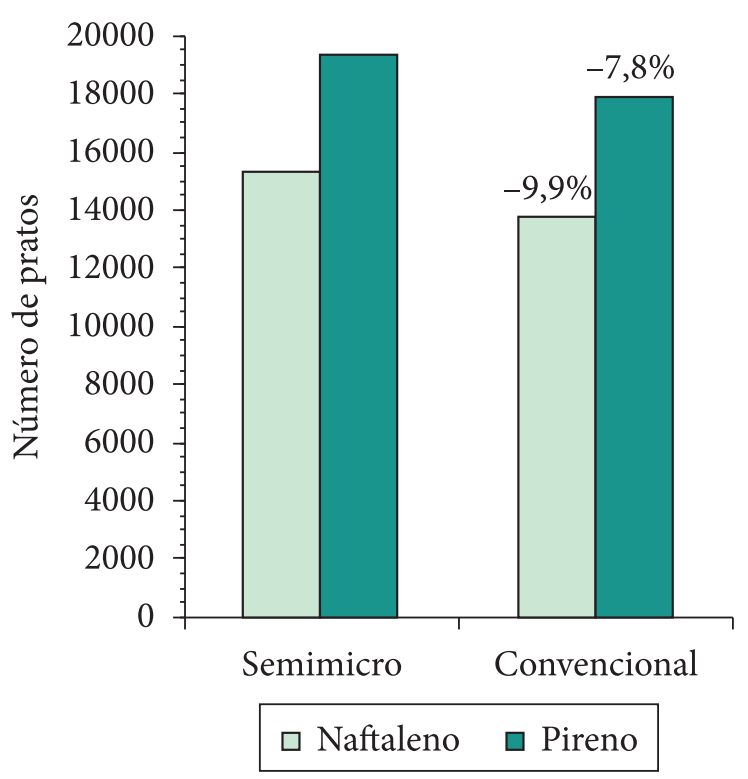

Figura 2 Comparação entre as eficiências máximas obtidas para os picos do naftaleno e pireno usando uma célula de deteç̧ão convencional e uma célula semimicro. Condições gerais: detecção a $10 \mathrm{~Hz}$, filtro de resposta de 0,02 segundos, fase móvel $A C N: \mathrm{H}_{2} \mathrm{O}$, 60:40 (v/v), volume de injeção de $1 \mu \mathrm{L}$ e temperatura do forno a $40{ }^{\circ} \mathrm{C}$. Vazões utilizadas: $0,8 \mathrm{~mL} / \mathrm{min}$ para o naftaleno e $0,7 \mathrm{~mL} / \mathrm{min}$ para o pireno. 
levando a uma redução de $60 \%$ da razão sinal/ ruído desse pico com o uso da célula semimicro. Diante desse resultado, observa-se que a melhor eficiência contrasta com uma razão sinal/ruído inferior. Em situações reais, a escolha do analista deve ser ponderada de acordo com o parâmetro mais importante para a análise. Se o mais importante for a eficiência e, ainda, se um limite de detecção (LD) e quantificação (LQ) mais baixos não forem necessários, a célula semimicro torna-se então a melhor escolha. Por outro lado, se a eficiência não for tão limitante, mas sim a busca por menores valores de LD e LQ, a escolha pelo uso da célula convencional deve ser considerada. Uma sugestão seria a verificação da influência de ambas as células frente à situação real de análise. Um exemplo pode ser observado na Figura 3, onde se normaliza e detalha uma região do cromatograma da separação de padrões de FQ em uma célula convencional e em uma célula semimicro. Observa-se que há uma perda de eficiência com o uso da célula convencional, porém essa perda não chega a ser crítica para a separação em questão. Numericamente há uma redução na resolução do primeiro par de 2,34 para 1,62 e do segundo par de 1,99 para 1,48; todavia a razão sinal/ruído com a célula convencional é o dobro daquela obtida com a célula semimicro.

Para obter-se a eficiência intrínseca da coluna e ter uma estimativa da variância extracoluna obtida com o sistema em condições ótimas de análise, foi construída uma curva das variâncias dos picos dos $\mathrm{PAH}$ em função dos volumes de retenção ao quadrado. Como foi demonstrado no artigo anterior ${ }^{[1]}$, o valor do intercepto desse gráfico equivale à variância extracoluna e a inclinação, ao inverso da eficiência $(1 / \mathrm{N})$. A Figura 4 ilustra essa curva, onde se verifica uma variância de $63 \mu \mathrm{L}^{2}$ e uma eficiência de 19594 pratos.

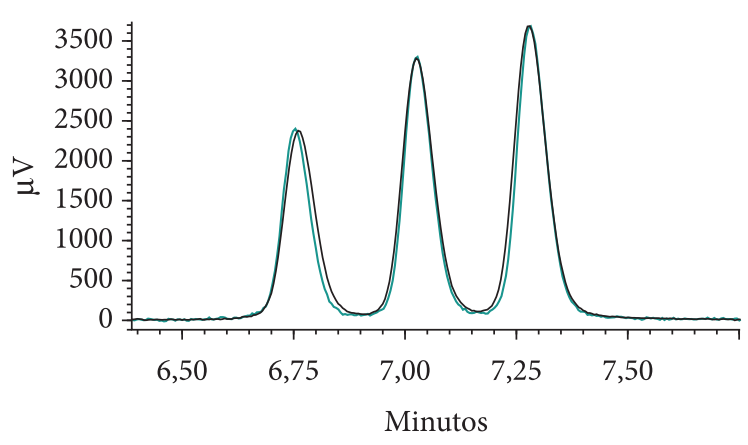

Figura 3 Destaque de uma parte dos cromatogramas normalizados das FQ comparando uma célula semimicro (verde) e uma célula convencional (preto). Os picos correspondem a levofloxacina, pefloxacina e ciprofloxacina (em ordem crescente de retenção). Os cromatogramas foram normalizados para obterem-se intensidades iguais, de maneira a favorecer a comparação do alargamento das bandas. Condições gerais: detecção a $3,3 \mathrm{~Hz}$, filtro de resposta de 0,02 segundos, separação por gradiente, temperatura do forno a $40{ }^{\circ} \mathrm{C}$, vazões de $0,6 \mathrm{~mL} / \mathrm{min}$ e volume de injeção de $2 \mu \mathrm{L}$.

\subsection{Avaliação do teste 2 - condições do detector}

Conforme mencionado anteriormente, as condições de aquisição e atenuação do ruído configuradas para a detecção dos picos cromatográficos podem causar prejuízos à eficiência cromatográfica. Por outro lado, com o aumento da frequência de aquisição e redução no tempo de resposta do detector (responsável pela atenuação do ruído), um aumento do ruído da linha de base é observado, levando à redução da relação sinal/ ruído dos picos detectados. O detector utilizado nesses experimentos tinha a capacidade de trabalhar com aquisição máxima de $10 \mathrm{~Hz}$ e com um filtro de resposta mínimo de 0,02 segundos. É importante ressaltar o aumento recente no número de modelos de detectores de diversos fabricantes, capazes de atuar em frequências mais altas de aquisição, justamente pela demanda trazida pela UHPLC e cromatografia rápida. Com relação à frequência de aquisição, um valor 
adequado pode ser estimado pelos picos mais estreitos de interesse, calculando-se a frequência mínima para a aquisição de, ao menos, 20 pontos ao longo da banda cromatográfica. Por serem valores facilmente configurados via software, o teste das melhores condições de aquisição do cromatograma pode ser facilmente executado. As Figuras 5 e 6 ilustram o efeito de diferentes condições de detecção para picos da mistura de PAH. A redução na frequência de aquisição de $10 \mathrm{~Hz}$ para $3,3 \mathrm{~Hz}$ causou uma redução de 6 a $7 \%$ na eficiência para os picos dos $\mathrm{PAH}$, sabendo que o pico mais afetado costuma ser aquele menos retido, e, por consequência, mais estreito. Por outro lado, a mudança citada acima elevou a razão sinal/ruído do pireno em $28 \%$ devido ao menor ruído observado na linha de base e ligeiro aumento na intensidade do pico cromatográfico. Como pode ser observado, o uso de um tempo de resposta maior (0,5 segundos), ou mesmo uma frequência menor $(1 \mathrm{~Hz})$, provoca perdas excessivas de eficiência, especialmente para os picos menos retidos. Com relação ao ruído da linha de base, um aumento excessivo do tempo de resposta não contribui tanto quanto a redução na frequência de aquisição, com base nos resultados apresentados, de modo que o aumento de 0,02 para 0,5 segundos, mantendo a frequência em 3,3 Hz, elevou de 28 para $32 \%$ os ganhos em relação à condição $10 \mathrm{~Hz}$ e 0,02 segundos.

De acordo com a discussão anterior, o ajuste da frequência de aquisição deve levar em conta a situação real de análise. Tomando como exemplo a separação das fluoroquinolonas apresentada na Figura 7, para a largura apresentada pelos picos, uma frequência de $3,3 \mathrm{~Hz}$ foi suficiente. Pode-se observar, pela comparação dos cromatogramas, que o perfil e largura dos picos mantiveram-se idênticos, tendo-se de diferença apenas a redução do ruído da linha de base; fato esse que dobra a relação sinal/ruído desses analitos. $\mathrm{O}$ detalhe

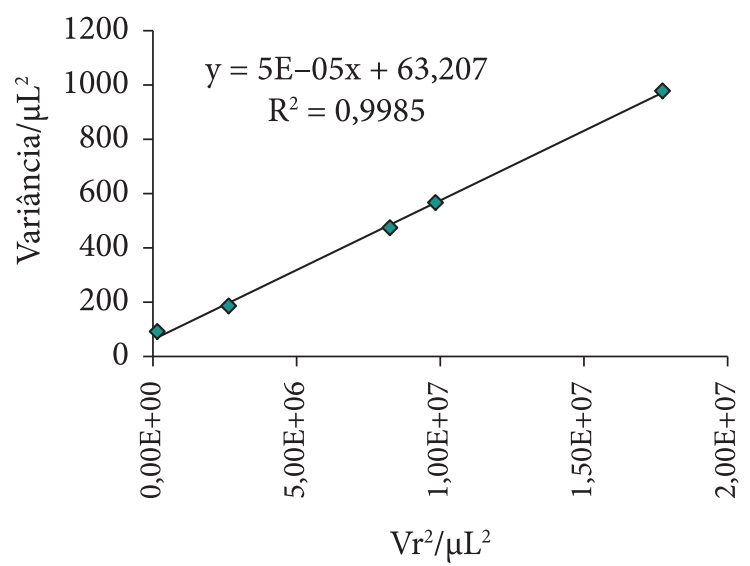

Figura 4 Gráfico da variância em função do quadrado do volume de retenção para a análise da mistura de PAH. Condições gerais: detecção a $10 \mathrm{~Hz}$, filtro de resposta de 0,02 segundos, célula semimicro, fase móvel $\mathrm{ACN}: \mathrm{H}_{2} \mathrm{O}$, 60:40 (v/v), volume de injeção de $1 \mu \mathrm{L}$, temperatura do forno a $40{ }^{\circ} \mathrm{C}$ e vazão a $0,8 \mathrm{~mL} / \mathrm{min}$.

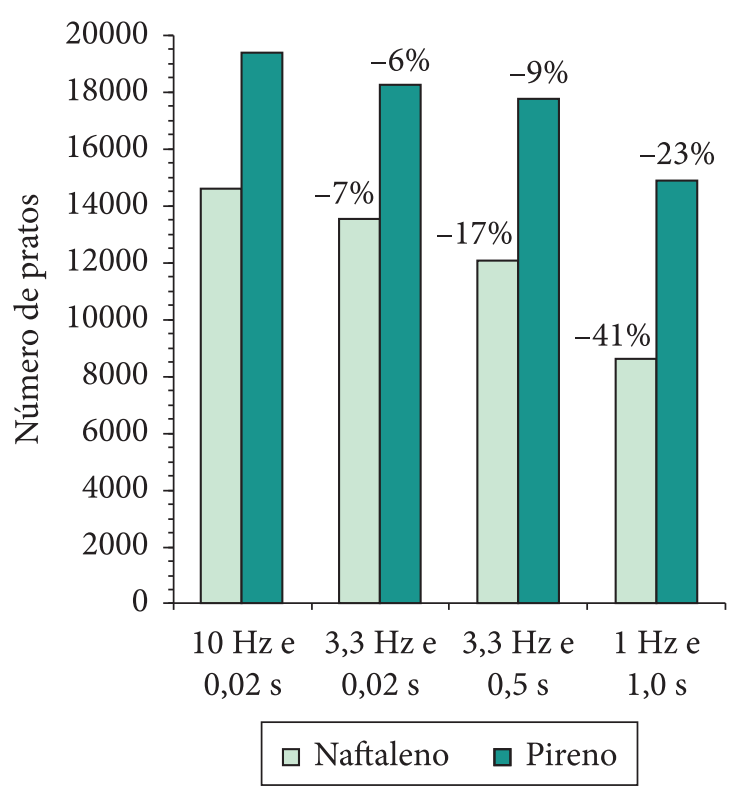

Figura 5 Comparação entre as eficiências obtidas para os picos do naftaleno e pireno usando diferentes frequências e tempos de resposta do detector. Condições gerais: fase móvel $\mathrm{ACN}: \mathrm{H}_{2} \mathrm{O}, 60: 40$ (v/v), volume de injeção de $1 \mu \mathrm{L}$, temperatura do forno a $40{ }^{\circ} \mathrm{C}$, vazão de $0,8 \mathrm{~mL} / \mathrm{min}$ e célula semimicro.

da Figura 7 demonstra que as bandas cromatográficas de ambas as aquisições foram perfeitamente sobrepostas, ressaltando que a redução de frequência não trouxe prejuízo para a efi- 
ciência. É importante ressaltar que essa análise foi realizada a uma vazão de $0,5 \mathrm{~mL} / \mathrm{min}$, sob aproximadamente 200 bar de pressão; em uma

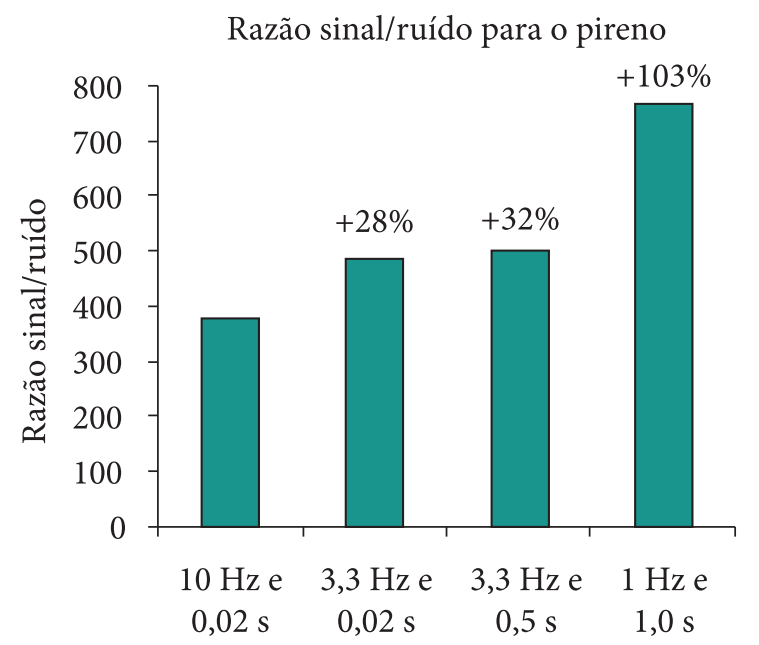

Figura 6 Comparação entre as razões sinal/ruído para o pico do pireno usando diferentes frequências e tempos de resposta do detector. Condições gerais: fase móvel $\mathrm{ACN}: \mathrm{H}_{2} \mathrm{O}, 60: 40(\mathrm{v} / \mathrm{v})$, volume de injeção de $1 \mu \mathrm{L}$, temperatura do forno a $40{ }^{\circ} \mathrm{C}$, vazão de $0,7 \mathrm{~mL} / \mathrm{min}$ e célula semimicro. condição mais rápida de análise, por exemplo, triplicando-se a vazão e chegando-se ao limite de pressão recomendado para a coluna, ao menos o triplo da frequência de aquisição desse experimento deveria ser utilizado.

\subsection{Avaliação do teste 3 - volume das tubulações}

É reconhecido que o volume excessivo das tubulações é uma das principais fontes de problemas de alargamento de picos em equipamentos antigos, não configurados para cromatografia rápida. A Figura 8 ilustra o quanto o excesso de volume nas tubulações pode atrapalhar a eficiência cromatográfica. Comparando-se diferentes tubos na ligação entre o injetor e a coluna, pode-se observar a crítica influência dessa variável. O comprimento mínimo de tubulação necessária para conectar a coluna (colocada no forno) à válvula de injeção do amostrador automático é de $30 \mathrm{~cm}$, sendo que,

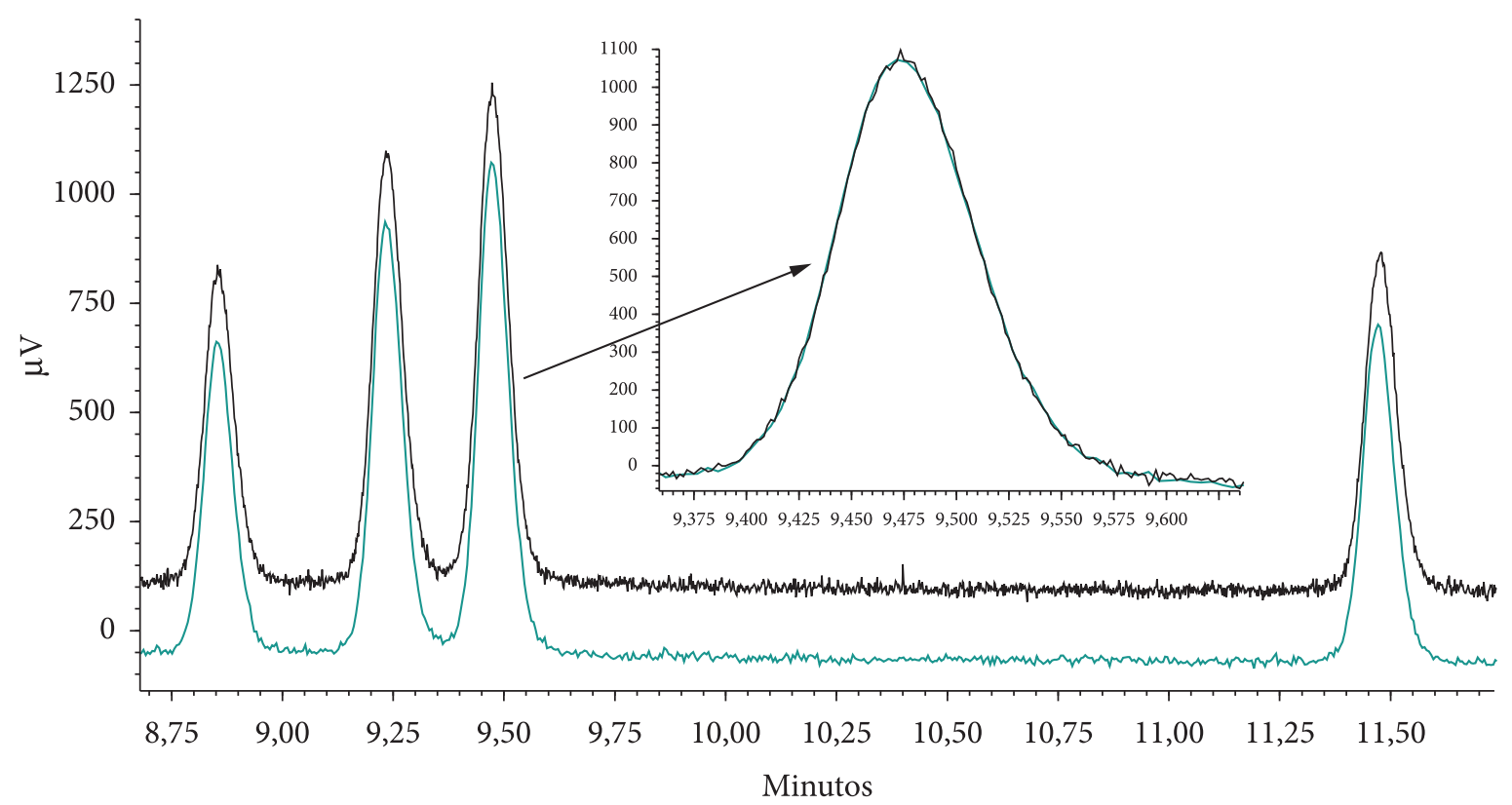

Figura 7 Parte dos cromatogramas das FQ comparando a aquisição em $3,3 \mathrm{~Hz}$ e 0,02 segundos (verde) com a aquisição em $10 \mathrm{~Hz}$ e 0,02 segundos (preto). Os picos correspondem a levofloxacina, pefloxacina, ciprofloxacina e enrofloxacina (em ordem crescente de retenção). No destaque, a sobreposição não normalizada do pico da ciprofloxacina nas duas condições de detecção. Condições gerais: separação por gradiente, temperatura do forno a $30^{\circ} \mathrm{C}$, vazão de $0,5 \mathrm{~mL} / \mathrm{min}$, volume de injeção de $1 \mu \mathrm{L}$ e célula semimicro. 


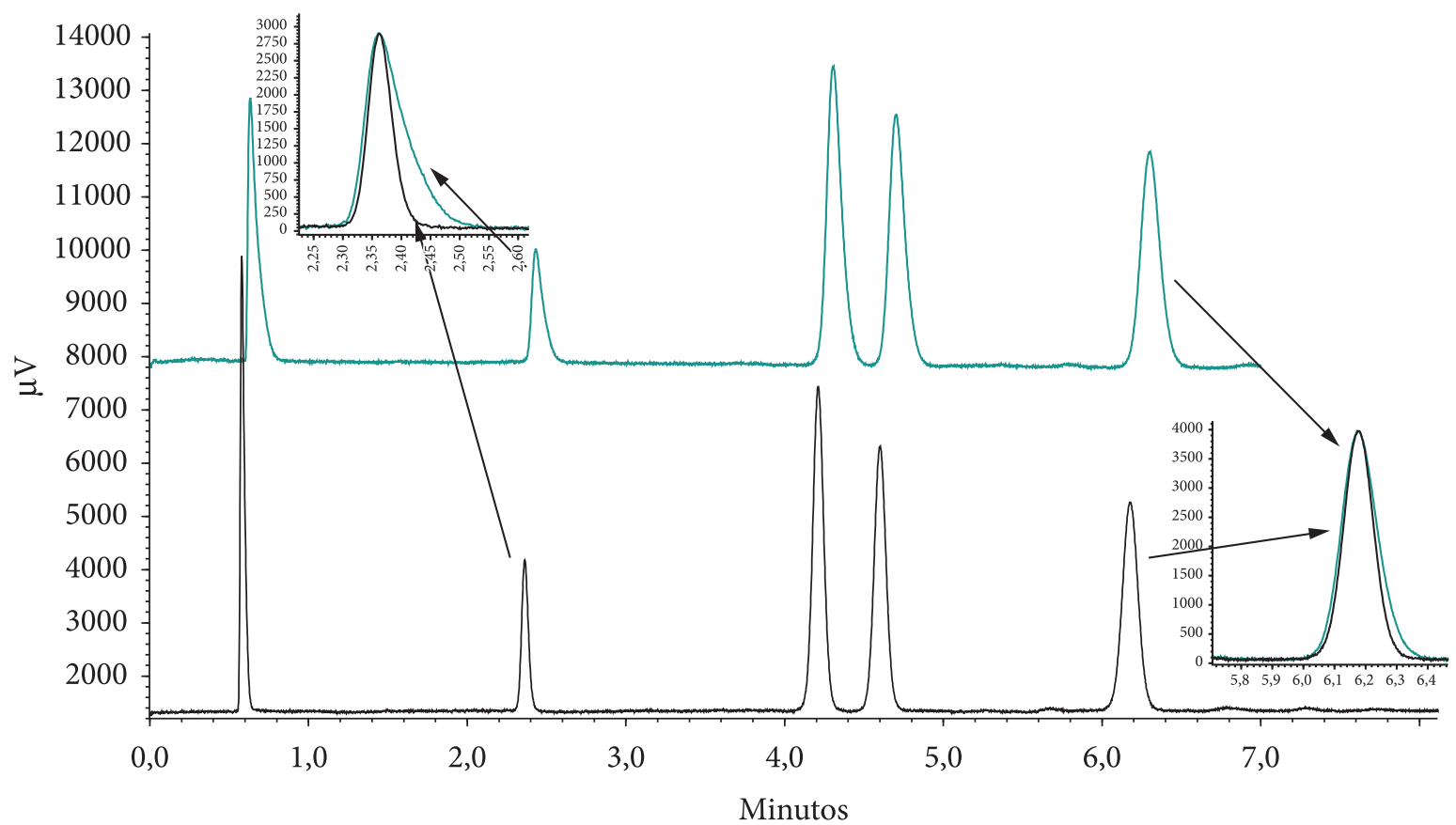

Figura 8 Cromatogramas normalizados dos PAH comparando tubulação pré-coluna com $60,8 \mu \mathrm{L}$ (verde) e 7,6 $\mu \mathrm{L}$ (preto). Os picos correspondem a naftaleno, antraceno, fenantreno e pireno (em ordem crescente de retenção). No destaque, a sobreposição, normalizada para a altura, dos picos cromatográficos, ilustrando o maior alargamento do pico menos retido. Condições gerais: fase móvel $\mathrm{ACN}: \mathrm{H}_{2} \mathrm{O}, 60: 40$ (v/v), volume de injeção de $1 \mu \mathrm{L}$, temperatura do forno a $40{ }^{\circ} \mathrm{C}$, vazão de $0,7 \mathrm{~mL} / \mathrm{min}$, célula semimicro, detecção a $10 \mathrm{~Hz}$ e tempo de resposta de 0,02 segundos. Tubulação com aproximadamente $60,8 \mu \mathrm{L}$ correspondente a $30 \mathrm{~cm}$ de tubo de PEEK alaranjado (508 $\mu \mathrm{m}$ d.i.) e com aproximadamente $7,6 \mu \mathrm{L}$ correspondente a $60 \mathrm{~cm}$ de tubo PEEK vermelho (127 $\mu \mathrm{m}$ d.i.).

com esse comprimento, o ajuste da coluna dentro do forno é bastante difícil. Idealmente, um tubo de $60 \mathrm{~cm}$ permite o ajuste da coluna na vertical, facilitando o manuseio e trocas de colunas. Comparando-se a utilização de tubos de PEEK vermelho (127 $\mu \mathrm{m}$ d.i.) de 30 e $60 \mathrm{~cm}$, não se observou qualquer diferença no cromatograma dos $\mathrm{PAH}$, inclusive para o pico da uracila, o qual tem fator de retenção praticamente nulo. Por outro lado, o uso de um tubo inapropriado, mesmo que no menor comprimento possível (tubo laranja com $30 \mathrm{~cm}$ ), provocou perdas enormes de eficiência. $\mathrm{O}$ pico do pireno na Figura 8 apresenta uma redução de $34 \%$ em sua eficiência, enquanto o pico do naftalento (menos retido) é demasiadamente alargado ao ponto de sofrer também um grande prejuízo em sua simetria.

\subsection{Avaliação do teste 4 - volume de injeção}

O volume de injeção máximo permitido em uma coluna, sem causar alargamento, depende do fator de retenção dos compostos de interesse, bem como da modalidade de análise. É sabido que a injeção da amostra em solução bem mais fraca do que a fase móvel leva à focalização dos analitos e que um efeito similar também é observado para os picos mais retidos em uma análise por gradiente. A Figura 9 demonstra que a injeção da mistura de PAH em volumes crescentes até $10 \mu \mathrm{L}$ não provocou o alargamento dos picos. Dado o fator de retenção de todos os analitos e o percentual de acetonitrila utilizada na fase móvel isocrática (60\%), observa-se que tanto o naftaleno quanto o pireno (o menos e mais retido dos analitos, respectivamente) foram bem focalizados. 
Por outro lado, a separação das sulfonamidas é um excelente exemplo do poder de focalização de uma análise em gradiente e dos problemas causados aos picos não focalizados no caso de excessivo volume de injeção. A mistura das sulfonamidas utilizada é composta por moléculas polares com diferentes graus de hidrofobicidade. A análise dessas SF é iniciada com fase móvel contendo apenas $8 \%$ de ACN em sua composição, tendo esse teor aumentado gradativamente até $33 \%$ ao fim da análise. Dessa forma, os primeiros picos eluem em fase móvel
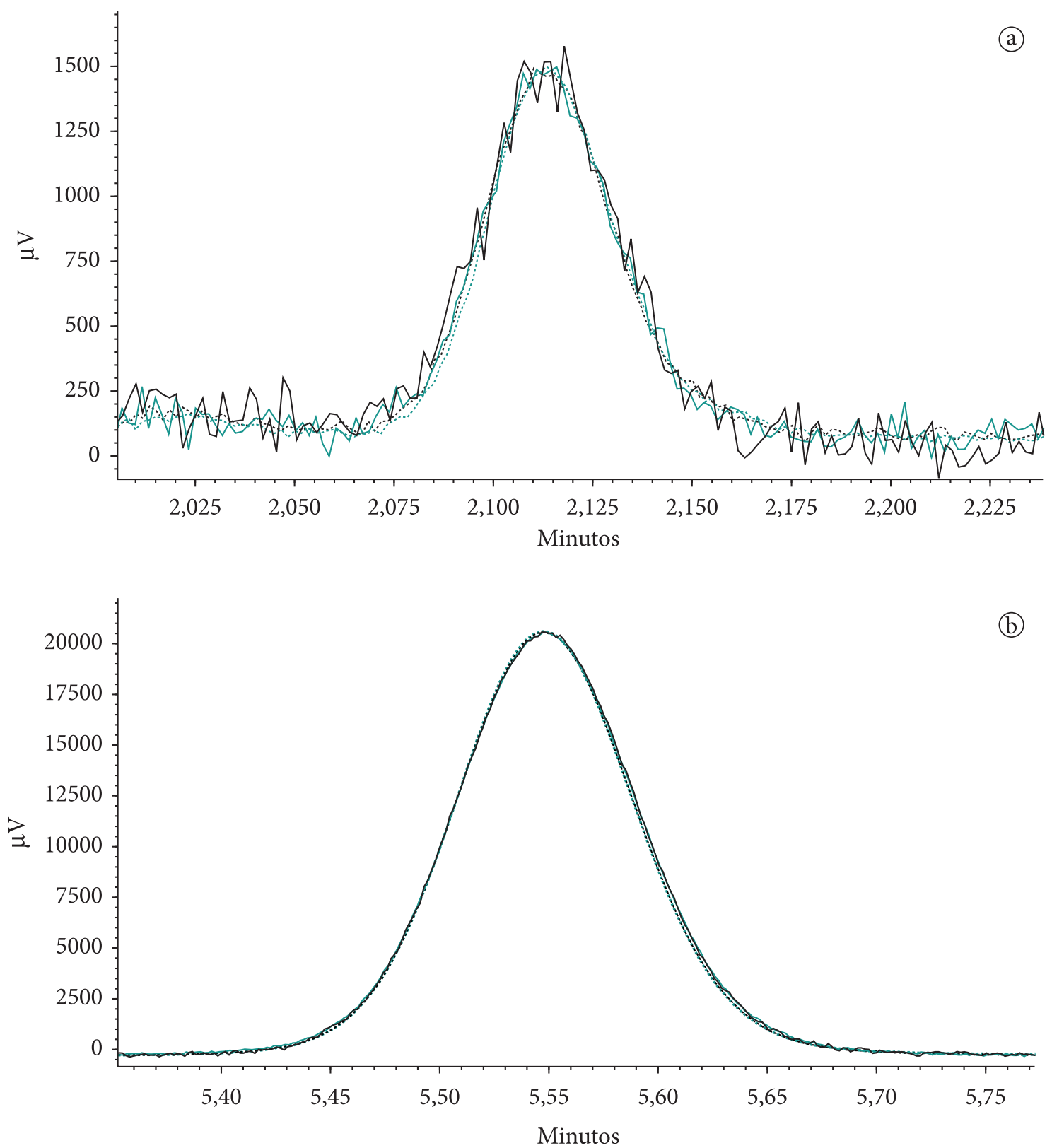

Figura 9 Detalhe de picos cromatográficos normalizados para a altura, comparando diferentes volumes de injeção $(1,2,5$ e $10 \mu \mathrm{L})$ - a) pico do naftaleno, b) pico do pireno - e ilustrando ausência de perda de eficiência para injeções de até $10 \mu \mathrm{L}$ sob as condições utilizadas. Condições gerais: fase móvel $\mathrm{ACN}: \mathrm{H}_{2} \mathrm{O}, 60: 40(\mathrm{v} / \mathrm{v})$, temperatura do forno a $40{ }^{\circ} \mathrm{C}$, vazão de $0,8 \mathrm{~mL} / \mathrm{min}$, célula semimicro, detecção a $10 \mathrm{~Hz}$, tempo de resposta de 0,02 segundos e mistura dos padrões analíticos preparada em fase móvel. 
muito fraca, incapaz de permitir a focalização dos analitos injetados em água. Todavia, os últimos picos, eluídos em uma fase móvel mais forte, são satisfatoriamente focalizados, conforme se observa na Figura 10. Nessa figura, fica nítido o alargamento do pico da sulfacetamida com os volumes crescentes de injeção, enquanto o último par de analitos não sofre qualquer alargamento mesmo quando $10 \mu \mathrm{L}$ de solução são injetados.
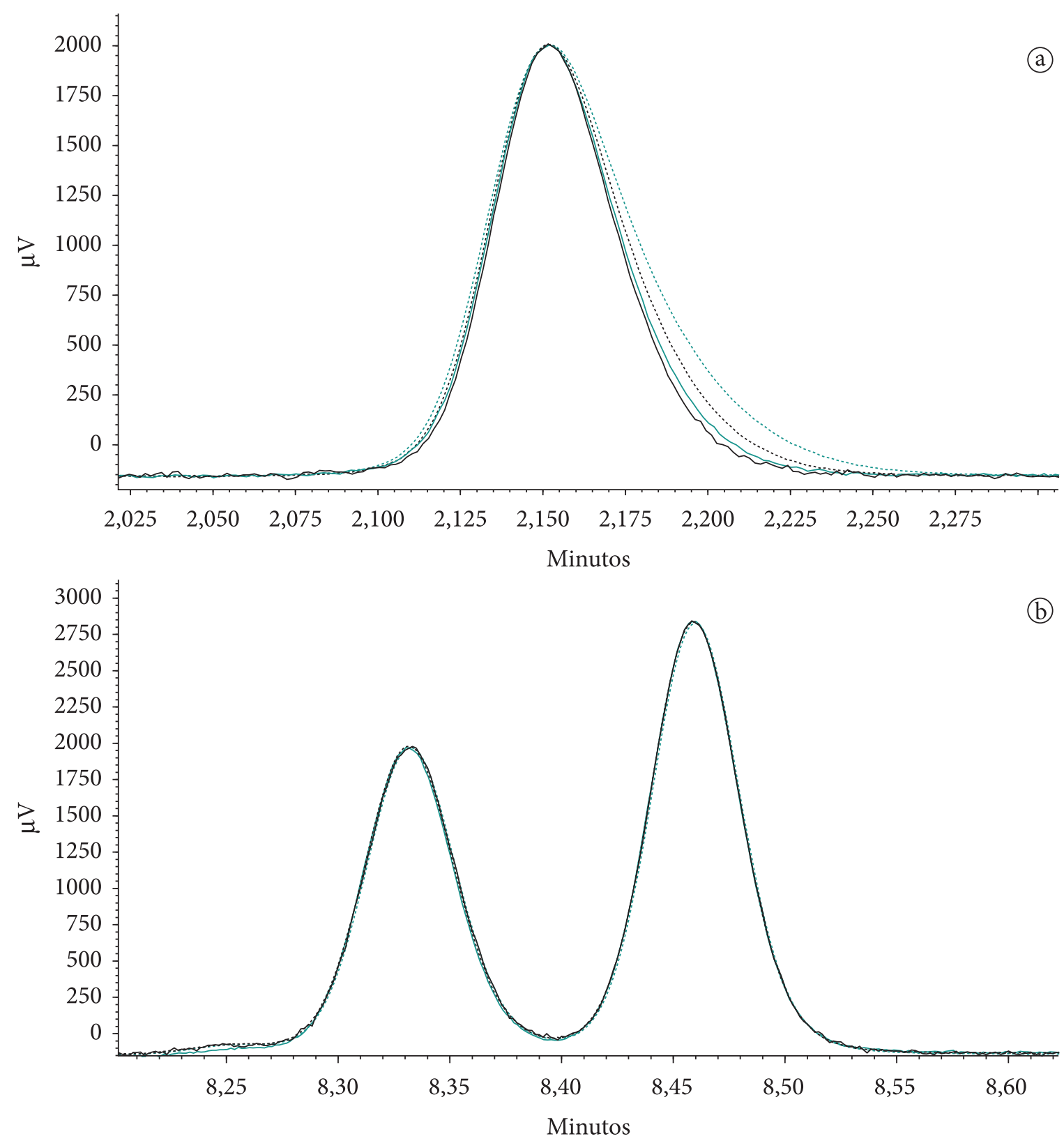

Figura 10 Detalhe de picos cromatográficos normalizados para a altura, comparando diferentes volumes de injeção (1, 2, 5 e $10 \mu \mathrm{L}$ ) - a) pico da sulfacetamida (padrão menos retido da mistura de sulfonamidas), b) picos da sulfadimethoxina e da sulfaquinoxalina (padrões mais retidos da mistura de sulfonamidas) - e ilustrando a focalização dos maiores volumes injetados para os picos mais retidos em relação ao menos retido. Condições gerais: análise em gradiente, temperatura do forno a $40{ }^{\circ} \mathrm{C}$, vazão de $0,6 \mathrm{~mL} / \mathrm{min}$, célula semimicro, detecção a $10 \mathrm{~Hz}$ e tempo de resposta de 0,02 segundos. 


\subsection{Avaliação comparativa das separações}

Algumas comparações foram feitas de maneira a apresentar as condições máximas de eficiência que puderam ser obtidas com o sistema cromatográfico utilizado, alguns ajustes racionais que puderam melhorar outros aspectos da análise, sem um detrimento importante da eficiência, bem como condições críticas de dispersão extracoluna que devem ser evitadas.

A Figura 11 compara uma condição máxima de eficiência obtida a $30^{\circ} \mathrm{C}$ para a análise das sulfonamidas, usando as condições de menor dispersão provocadas pelo volume de injeção, tubulação e sistema de deteç̧ão. Um aspecto interessante a ser observado é que, usando análise por gradiente, iniciando com
$8 \%$ de acetonitrila e temperatura de $30{ }^{\circ} \mathrm{C}$, uma vazão de $0,5 \mathrm{~mL} / \mathrm{min}$ já levava o sistema a aproximar-se do limite de 200 bar estabelecido pelo amostrador automático utilizado. Uma forma de aumentar a vazão a $0,6 \mathrm{~mL} / \mathrm{min}$ e diminuir o tempo de análise foi a utilização de uma temperatura de $40^{\circ} \mathrm{C}$, a qual diminui a viscosidade da fase móvel. Essa nova condição permitiu uma redução no tempo total de análise (cromatograma central). Adicionalmente, deve-se levar em consideração que a utilização de sistemas que suportam até 400 ou 600 bar ainda permitiria a redução do tempo de análise na proporção do aumento da vazão. Para conseguir um ganho na detectabilidade, além do ajuste da vazão, utilizou-se um maior volume de injeção $(2 \mu \mathrm{L})$ e uma célula convencional

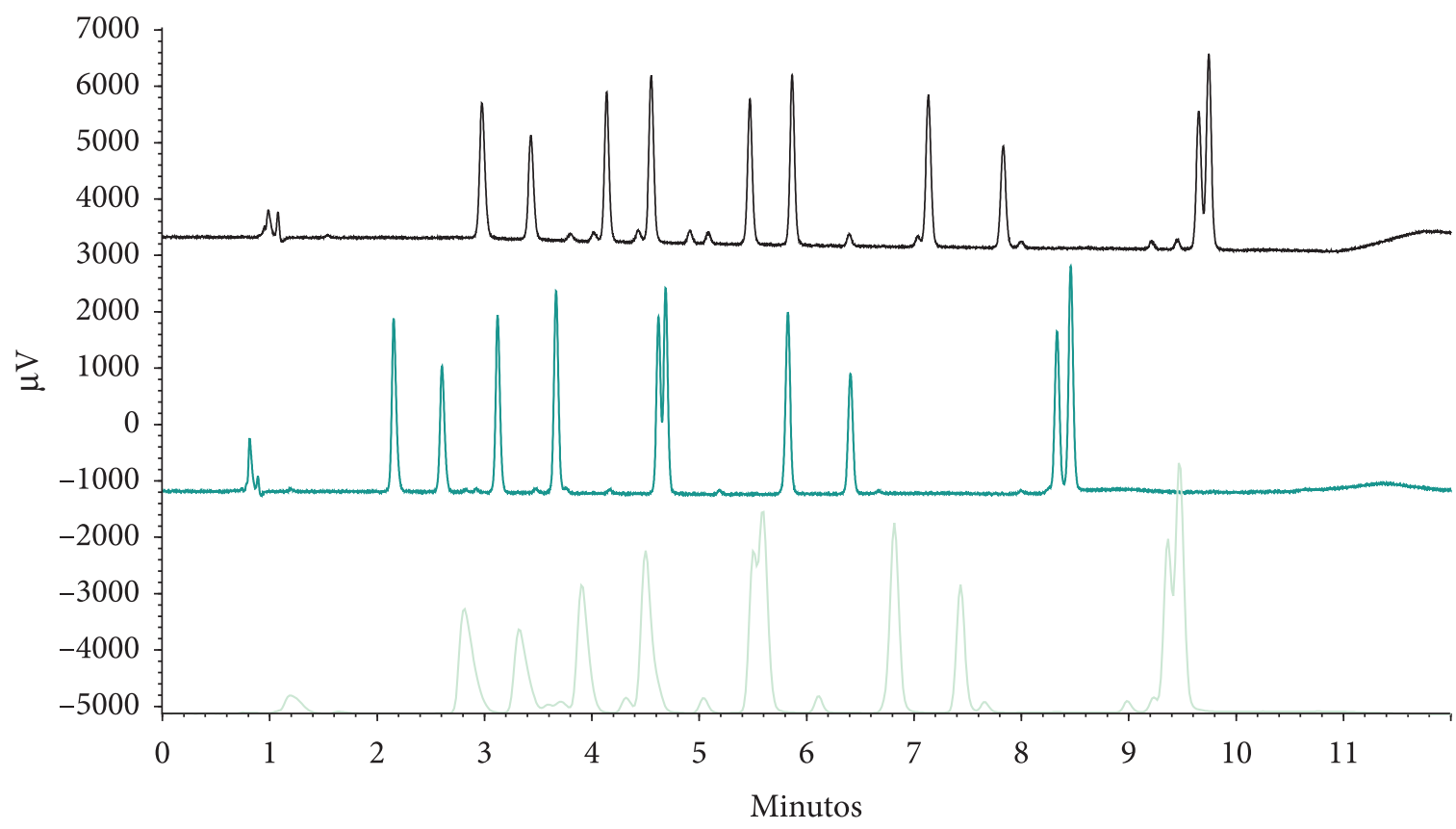

Figura 11 Cromatogramas normalizados da mistura de sulfonamidas. Preto: Separação em sistema com a menor possível dispersão extracoluna - detecção a $10 \mathrm{~Hz}$, tempo de resposta de 0,02 segundos, célula semimicro, volume de injeção de $1 \mu \mathrm{L}$, tubulação vermelha pré-coluna, temperatura de $30^{\circ} \mathrm{C}$ e vazão de $0,5 \mathrm{~mL} / \mathrm{min}$. Verde: Separação racionalizada - detecção a $10 \mathrm{~Hz}$, tempo de resposta de 0,02 segundos, célula convencional, volume de injeção de $2 \mu \mathrm{L}$, tubulação vermelha pré-coluna, temperatura de $40{ }^{\circ} \mathrm{C}$ e vazão de $0,6 \mathrm{~mL} / \mathrm{min}$. Verde-claro: Separação sob configuração inadequada - detecção a $1,0 \mathrm{~Hz}$, tempo de resposta de 1,0 segundo, célula convencional, volume de injeção de $10 \mu \mathrm{L}$, tubulação alaranjada pré-coluna, temperatura de $40{ }^{\circ} \mathrm{C}$ e vazão de $0,6 \mathrm{~mL} / \mathrm{min}$. Mistura constituída por sulfacetamida, sulfadiazina, sulfatiazol, sulfamerazina, sulfametazina, sulfametazol, sulfacloropiridazina, sulfametoxazol, sulfadimetoxina e sulfaquinoxalina (em ordem crescente de retenção). 
de detecção, sem que um grande prejuízo da separação possa ser visualizado. Um último detalhe a ser destacado é que ajustes na temperatura podem provocar variações na seletividade, como pode ser observado na melhoria da resolução do último par de picos cromatográficos e na piora na resolução entre o quinto e o sexto pico. Por fim, apresenta-se uma condição totalmente crítica de análise, a qual demonstra o quanto um ajuste inadequado das condições cromatográficas em uma eventual transferência de método poderia provocar prejuízos na separação dos mesmos analitos.

De maneira similar, a Figura 12 faz a mesma comparação para as fluoroquinolonas, com o detalhe que, para os quatro compostos analisados, não se observou influência da temperatura sobre a seletividade. A frequência de aquisição pôde ser ajustada a 3,3 Hz, uma vez que, com a largura dos picos das $\mathrm{FQ}$, foi possível a aquisição de 20 pontos/pico. Como pode ser observado entre o cromatograma superior e o central, há pequena diminuição da resolução; todavia, além de não ser uma redução crítica para a separação em questão, essas modificações do método levaram a menor tempo de análise e significativa melhora na relação sinal/ruído dos picos.

Finalmente, a Figura 13 ilustra o ganho em eficiência e tempo de análise ao se migrar de uma velocidade de análise típica de HPLC convencional para a velocidade ótima de análise desse tipo de coluna. A pressão exigida do cromatógrafo para obter-se o cromatograma a $0,8 \mathrm{~mL} / \mathrm{min}$, sob as condições descritas, é pró-

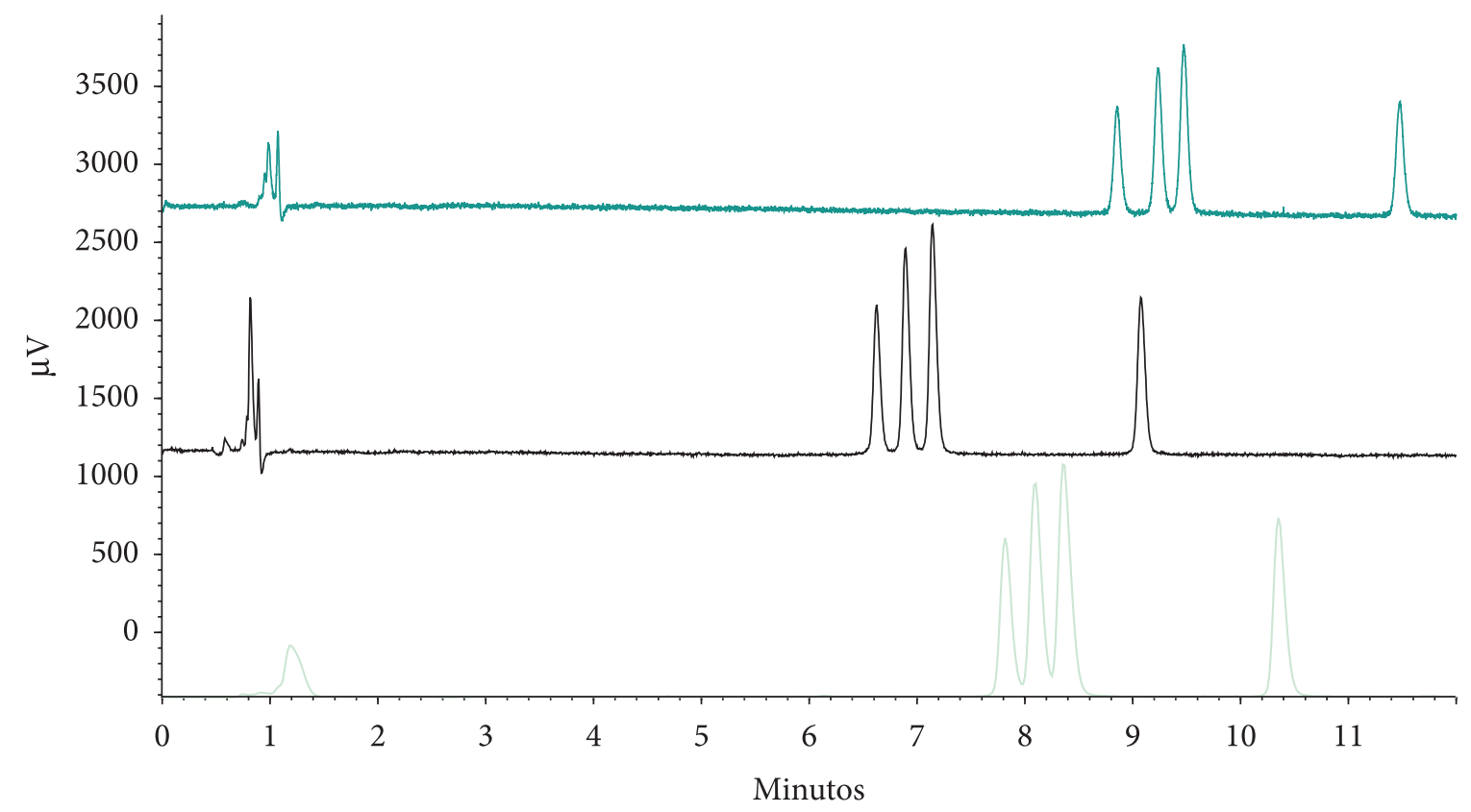

Figura 12 Cromatogramas normalizados da mistura de fluoroquinolonas. Verde: Separação em sistema com a menor possível dispersão extracoluna - detecção a $10 \mathrm{~Hz}$, tempo de resposta de 0,02 segundos, célula semimicro, volume de injeção de $1 \mu \mathrm{L}$, tubulação vermelha pré-coluna, temperatura de $30{ }^{\circ} \mathrm{C}$ e vazão de $0,5 \mathrm{~mL} / \mathrm{min}$. Preto: Separação racionalizada - detecção a 3,3 Hz, tempo de resposta de 0,02 segundos, célula convencional, volume de injeção de $2 \mu \mathrm{L}$, tubulação vermelha pré-coluna, temperatura de $40{ }^{\circ} \mathrm{C}$ e vazão de $0,6 \mathrm{~mL} / \mathrm{min}$. Verde-claro: Separação sob configuração inadequada - detecção a 1,0 Hz, tempo de resposta de 1,0 segundo, célula convencional, volume de injeção de $10 \mu \mathrm{L}$, tubulação alaranjada pré-coluna, temperatura de $40{ }^{\circ} \mathrm{C} \mathrm{e}$ vazão de 0,6 mL/min. Mistura constituída por levofloxacina, pefloxacina, ciprofloxacina e enrofloxacina (em ordem crescente de retenção). 


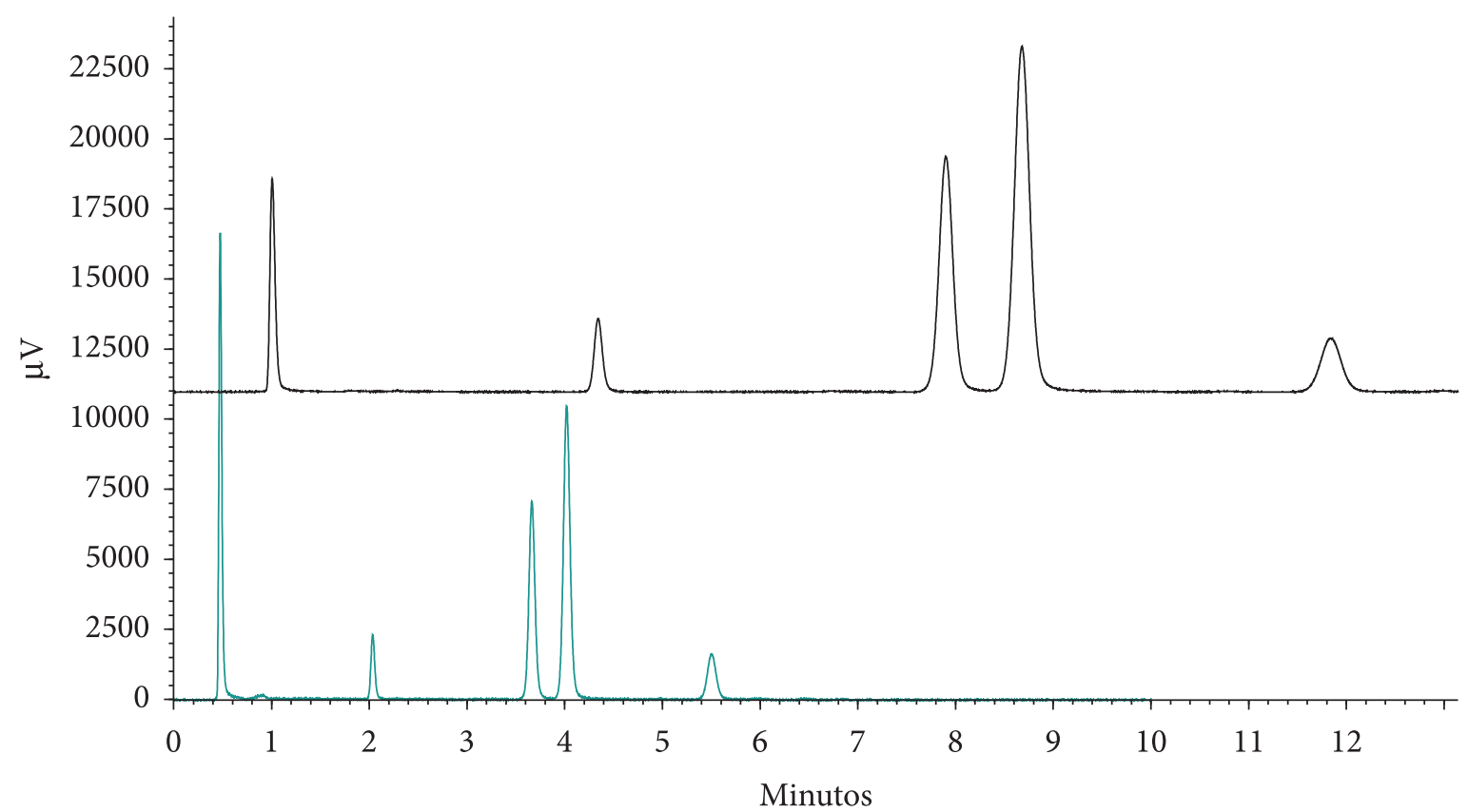

Figura 13 Cromatogramas normalizados da mistura de PAH. Preto: Separação a 0,4 mL/min, verde: separação a $0,8 \mathrm{~mL} / \mathrm{min}$. Mistura constituída por uracila, naftaleno, antraceno, fenantreno e pireno (em ordem crescente de retenção). Condições gerais: fase móvel $\mathrm{ACN}: \mathrm{H}_{2} \mathrm{O}, 60: 40(\mathrm{v} / \mathrm{v})$, detecção a $10 \mathrm{~Hz}$, tempo de resposta de 0,02 segundos, célula semimicro, volume de injeção de $1 \mu \mathrm{L}$, tubulação vermelha pré-coluna e temperatura de $30^{\circ} \mathrm{C}$.

xima a 200 bar. Considerando que o termo C da equação de van Deemter para essas colunas não é muito pronunciado, vazões ainda mais altas podem ser facilmente exploradas até a pressão limite de 600 bar imposta pela coluna, desde que o sistema cromatográfico utilizado suporte essas condições de uso.

\section{Considerações finais}

Como se pôde observar nas Figuras 11 e 12, condições inadequadas de análise destruíram toda a eficiência intrínseca de colunas cromatográficas de excelente qualidade, chegando até mesmo a eficiências inferiores àquelas observadas em HPLC convencional. Conforme foi descrito no artigo da última edição e exemplificado no presente artigo, um mínimo de cuidado na seleção dos parâmetros de análise pode levar a excelentes resultados, quer queira, em busca da máxima eficiência; ou, até mesmo, na aceitável, controlada e deliberada perda de uma pequena parcela dessa eficiência em função de um ganho na detectabilidade.

A coluna SSP sub-3 $\mu$ m usada neste trabalho apresentou adequado desempenho, com economia de solventes, por se tratar de uma coluna do tipo "solvent saver". Apesar da limitação de pressão máxima imposta pelo amostrador automático (200 bar), as colunas ainda puderam ser utilizadas em proximidade ao seu máximo de eficiência, ou até acima dele, a depender da viscosidade da fase móvel, temperatura de análise e características da molécula. Recomenda-se, contudo, que, idealmente, essas colunas sejam usadas em sistemas HPLC que suportem até 600 bar de pressão, condição essa capaz de garantir o máximo de velocidade de análise oferecido por esse tipo de material de preenchimento. 


\section{Agradecimentos}

Ao Sr. Alexandre Cruz (Sinc do Brasil) pela assistência na atualização e configuração da controladora do sistema HPLC. À Pró-Reitoria de Pós-Graduação da USP pelo auxílio financeiro via "Programa de Apoio aos Novos Docentes". Às agências de fomento CNPq, CAPES e FAPESP (Proc. $n^{\circ}$ 2010/19910-9) pelo fomento ao Grupo de Pesquisa em Cromatografia (CROMA) do IQSC/USP.

\section{Referências}

1 Santos-Neto AJ. Como obter maior eficiência com partículas superficialmente porosas em HPLC. Scientia Chromatographica 2011; 3(1):65. http:// dx.doi.org/10.4322/sc.2011.005

2 Majors RE. Transferring a Method from a Conventional $3.5 \mu \mathrm{m}$ or $5 \mu \mathrm{m}$ to an Agilent Poroshell 120 Column to Improve Analytical Speed and Resolution [cited 2011 jun]. Agilent Technologies, Inc., 2010. Video Notes. Available from: http://www.chem.agilent.com/Library/ datasheets/Public/Poroshell_120_video_notes.pdf.

3 MAC-MOD Analytical Inc. Technical Report LC507: How to Measure and Reduce HPLC Equipment Extra Column Volume [cited 2011 jun]. Available from: http:// www.mac-mod.com/pdf/MMA084-ReduceECV_ MM_Singles.pdf.

4 MAC-MOD Analytical Inc. Technical Report LC500: Quick Tips for Converting Conventional ReversedPhase HPLC Separations to Ultra-Fast Separations [cited 2011 jun]. Available from: http://www.mac-mod. com/pdf/MMA084-ReduceECV_MM_Singles.pdf.

5 MAC-MOD Analytical Inc. Technical Report: A Troubleshooting Guide to Plumbing Problems in HPLC [cited 2011 jun]. Available from: http://www. mac-mod.com/pdf/08_PlumbingTBS.pdf.

6 Maldaner L, Fontes Jardim ICS. O estado da arte da cromatografia líquida de ultra eficiência. Química Nova 2009; 32:214. http://dx.doi.org/10.1590/S010040422009000100036 